\title{
Hybrid aortic arch repair: Facts and hints beyond the statistical truth
}

\author{
Luca Salvatore De Santo, MD, FESC
}

\author{
From the University of Foggia, Foggia, and Cardiac Surgery Unit, Casa di Cura Montevergine, GVM Care \& \\ Research, Mercogliano, Italy. \\ Disclosures: Author has nothing to disclose with regard to commercial support. \\ Received for publication Dec 28, 2016; accepted for publication Jan 10, 2017; available ahead of print Feb 10 , \\ 2017. \\ Address for reprints: Luca Salvatore De Santo, MD, FESC, Department of Cardiac Surgery, Casa di Cura Mon- \\ tevergine, viale Colli Aminei 491, 80131, Naples, Italy (E-mail: luca.desanto@unifg.it). \\ J Thorac Cardiovasc Surg 2017; 154:107 \\ $0022-5223 / \$ 36.00$ \\ Copyright (c) 2017 by The American Association for Thoracic Surgery \\ http://dx.doi.org/10.1016/j.jtcvs.2017.01.004
}

Hybrid arch repair refers to a host of different approaches that combine supra-aortic vessel debranching and endovascular therapy that were developed to address aortic multisegmental pathologies in high-risk patients deemed unsuitable candidates for conventional surgery. The complexity of these approaches depends on the nature and extent of the aortic disease, which is often a surrogate marker for a patient's clinical profile. Several technical issues apply. The search for the optimal proximal landing zone, crucial for proper stent graft placement and sealing, has to conform to variable arch angulations, high blood flow, and the pulsatile movement of this aortic segment, as well as the technology of available prosthetic devices. On the other side, despite the reproducibility of the supra-aortic vessel transposition techniques not being a real issue at first sight, a learning curve effect is easily predictable when working within this anatomically neglected area. Besides the highly variable individual pattern of cerebral, spinal, or coronary vascularization, the prevention of embolization of atherosclerotic debris during surgical manipulation, the vulnerability to infectious complications of interposed prosthetic grafts, and the potential for vessel kinking or compression are all issues that should be carefully addressed to optimize outcomes. Inherent merits and indications are under active investigation and several studies and meta-analyses have tried to compare outcomes with conventional surgical therapy. ${ }^{1}$ Nevertheless, several biases largely prevent any definitive conclusion: a retrospective cohort design, a relatively small sample size, and limited length of follow-up time are the most common. Above all, the peculiar individual clinical mix of extent of aortic disease and frailty make these studies more case-report series than cohort studies.

Hiraoka and colleagues ${ }^{2}$ report on a propensity-score matching analysis. Following are some keys to interpretation. Nearly 15 years ago, an authoritative editorial pointed out the relevance of "statistics for the rest of us" and considerable efforts have been dedicated to educate surgeons. ${ }^{3}$ Did we take it too seriously? Indeed, Hiraoka and colleagues $^{2}$ endured a meticulous 3 -step review process to

\section{References} 207-8.

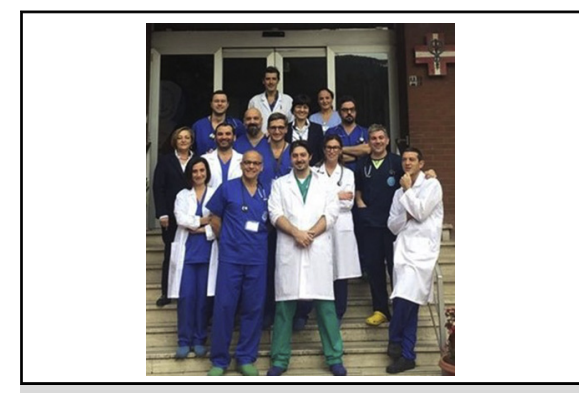

The cardiac surgery staff at Casa di Cura Montevergine, Mercogliano, Italy.

\section{Central Message}

Hybrid repair has effectively broadened the therapeutic armamentarium for aortic arch pathologies in frail patients. Technical refinements and a better definition of indications are needed.

See Article page 100.

address "the rigor with which statistical analyses are assessed." If readers had been able to peep through the keyhole, it would have been evident that even the overzealous reviewers' panel had difficulties in dealing with all of the statistics editor's suggestions. Can oranges and apples really be compared through propensity matching? Were all relevant eyeball clinical evaluations really taken into account? Did this analysis justify the complex craftsmanship needed to perform any individual hybrid repair? Do we really need to compare different strategies in the era of patient-tailored approaches? In the hands of a team with remarkable expertise in open surgery, nearly $16 \%$ of patients needed a nonconventional approach. Carefully tailored, but largely perfectible, hybrid approaches demonstrated equivalent midterm outcomes but higher rates of postoperative stroke.

Definitely not a short cut but rather an alternative path, hybrid repair certainly needs a better definition of indications. Too simple a message for surgical craftsmen?

1. Koullias GJ, Wheatley GH III. State-of-the-art hybrid procedures for the aortic arch: a meta-analysis. Ann Thorac Surg. 2010;90:689-97.

2. Hiraoka A, Chikazawa G, Totsugawa T, Tamura K, Ishida A, Sakaguchi, et al. Objective analysis of midterm outcomes of conventional and the hybrid aortic arch repai by propensity-score matching. J Thorac Cardiovasc Surg. 2017;154:100-6.e1.

3. Wechsler AS. Statistics for the rest of us. J Thorac Cardiovasc Surg. 2001;122: 